\title{
Evidence for reversible motoneurone dysfunction in thyrotoxicosis
}

\author{
A. J. McCOMAS, R. E. P. SICA, A. R. MCNABB, \\ W. M. GOLDBERG, AND A.R. M. UPTON \\ From the Department of Medicine, McMaster University, Hamilton, Ontario, Canada, \\ and the Canadian Medical Research Council's Developmental Neurobiology Research Group
}

SYNOPSIS Motor unit estimating techniques have been employed as part of a comprehensive electrophysiological survey of peripheral nerve and muscle in 20 patients with thyrotoxicosis. In all patients there was evidence of a loss of operational motor units; the selective nature of this involvement suggested that the motoneurone soma was the site of the primary lesion. The reversible nature of the postulated motoneurone dysfunction was demonstrated by the increased motor unit counts in six patients who were studied again after treatment of their thyrotoxicosis.

Patients with thyrotoxicosis will often admit to a feeling of weakness and may actually have evidence of muscle wasting; in some patients muscle fasciculations and painful muscle cramps may also occur. Only in recent years, however, has the extremely high incidence of myopathic features in thyrotoxicosis become apparent. In two especially thorough studies in which electromyographic criteria were used, evidence of 'myopathy' was found in $92.6 \%$ of thyrotoxic patients by Ramsay (1966) and in $80 \%$ by Havard et al. (1963). The results of histological examination of muscles in thyrotoxicosis have been more variable; for while Havard et al. (1963) found remarkably little abnormality, others have described such features as atrophy and degeneration of muscle fibres, invasion by macrophages and lymphocytes - the latter sometimes forming lymphorrhages-and fatty infiltration (Whitfield and Hudson, 1961 ; Schwarz and Rose, 1963).

In addition to the myopathy, there have been occasional reports of neuropathic changes complicating thyrotoxicosis. For example, Birket-Smith and Olivarius (1957) described one case of polyradiculitis, while Bronsky et al. (1964) collected four. The last authors considered that thyrotoxicosis favoured the development of the Guillain-Barré syndrome. The paper by Ludin et al. (1969) is rather different in that these workers deliberately sought electromyographice evidence of neuropathy in a population of 13 hyperthyroid patients and detected it in eight However, in spite of such definite findings, the prevailing opinion is that neuropathic changes ir thyrotoxicosis are uncommon and, if present reflect the presence of some additional aetio logical factor (Engel, 1973).

In the present study the problem has been reexamined using recently developed techniques for assessing function of individual motor units, and hence of motoneurones (see Methods). It will be shown that 'functional' denervation of muscle fibres occurs in nearly every patient presenting with thyrotoxicosis. The motoneurone dysfunction responsible for this denervation appears to be reversible once the thyrotoxicosis is brought under control. The possible relationship of the present findings to certain other neurological complications of thyrotoxicosis is discussed. A preliminary report on some of this work has already appeared (McComas et al., 1973).

\section{METHODS}

PATIENTS The major part of the study was conducted on 20 patients in whom the clinical diagnosis of thyrotoxicosis had been confirmed by standard radioisotope tests. These patients had either commenced treatment with ${ }^{131}$ I during the previous week 
or else were about to begin. Two other patients had recently presented with exophthalmos but neither clinically, nor on the basis of laboratory investigations, was there evidence of thyrotoxicosis. Since it is known that there is a loss of functioning motor units in healthy subjects beyond the age of 60 years (Campbell and McComas, 1970; Campbell et al., 1973), only patients below this age were studied. Although no one was rejected from the study other than for reasons of age, all but one of the 20 thyrotoxic patients were female. For each type of investigation control observations were made on a group of 20 healthy subjects who were matched for sex and, as closely as possible, for age (61 control subjects altogether). The results in these normal subjects resembled those obtained from a much larger population of males and females below the age of 60 who had previously been used for similar experiments. Informed consent was given by all the patients and controls after the nature of the experimental procedure had been explained; in addition, the approval of the Ethics Committee of McMaster University Medical Centre was obtained for this study.

MOTOR UNIT ESTIMATES The term 'motor unit' was originally employed by Sherrington (1931) to describe a single motoneurone and the colony of muscle fibres which it innervated. For convenience we shall follow common contemporary usage by referring to the muscle fibre colony as the motor unit and excluding the motoneurone. The method chosen for estimating the numbers and relative sizes of motor units in the extensor digitorum brevis (EDB) muscle has been reported previously (McComas et al., 1971). It involves the use of large electrodes to record the incremental potentials evoked in the EDB muscle by graded nerve stimulation. The method assumes that each increment in the response reflects the excitation of an additional motor unit. The number of units within the muscle can then be estimated by comparing the mean amplitude of the increments with the size of the maximal muscle response evoked by a larger stimulus to the nerve. The method has now been extended to the thenar and hypothenar muscles by ourselves (Sica et al., 1974) and independently by Brown (1972).

IMPULSE CONDUCTION VELOCITIES Measurements of maximum impulse conduction velocities were made for motor fibres in the peroneal, median, and ulnar nerves. Silver strips were attached to the skin over the end-plate zones of the appropriate muscles and served as stigmatic electrodes. Sensory nerve potentials were recorded with two chlorided silver disc electrodes mounted in a Perspex holder; the discs were $1 \mathrm{~cm}$ in diameter and their centres were $3.1 \mathrm{~cm}$ apart. The electrodes were mounted over the wrist to record orthodromically conducted impulses in digital nerve fibres of the radial, median and ulnar nerves. In contrast, the sural nerve potentials were recorded antidromically using stimulating electrodes over the calf and recording electrodes placed just below the lateral malleolus of the ankle.

The potentials were fed through a low-noise preamplifier, using a passband extending from $2 \mathrm{~Hz}$ to $1 \mathrm{kHz}$, and were then displayed on a Hewlett-Packard type 141B variable persistence-storage oscilloscope. The temperature of the recording room was maintained at $25-27^{\circ} \mathrm{C}$ and, in addition, the limbs were warmed with an infra-red lamp before study.

ISOMETRIC TWITCH The maximum tension and timecourse of the isometric twitch in EDB was also measured, using a specially designed foot-holder (Sica and McComas, 1971). The temperature of the skin overlying EDB was kept between $35-37^{\circ} \mathrm{C}$.

INTRAMUSCULAR ELECTROMYOGRAPHY In 13 patients a concentric needle electrode (Disa, type 9013L0501)

TABLE 1

MEAN VALUES ( \pm SD) FOR AMPLITUDES OF MAXIMUM EVOKED POTENTIALS (M WAVES) AND FOR NUMBERS OF MOTOR UNITS IN MUSCLES OF THYROTOXIC AND CONTROL SUBJECTS

\begin{tabular}{|c|c|c|c|c|c|c|}
\hline & \multicolumn{3}{|c|}{$M$ wave $(m V)$} & \multicolumn{3}{|c|}{ Motor units (no.) } \\
\hline & Controls & Patients & $P$ & Controls & Patients & $P$ \\
\hline Thenar & $\begin{array}{c}13 \cdot 7 \pm 6 \cdot 1 \\
(20)\end{array}$ & $\begin{array}{c}6 \cdot 8 \pm 2 \cdot 1 \\
(16)\end{array}$ & $<0.001$ & $\begin{array}{c}329 \pm 75 \\
(20)\end{array}$ & $\begin{array}{c}149 \pm 64 \\
(16)\end{array}$ & $<0.001$ \\
\hline Hypothenar & $\begin{array}{c}12 \cdot 8 \pm 3 \cdot 6 \\
(20)\end{array}$ & $\begin{array}{c}9 \cdot 3 \pm 2 \cdot 6 \\
(20)\end{array}$ & $<0.01$ & $\begin{array}{c}367 \pm 99 \\
(20)\end{array}$ & $\begin{array}{c}255 \pm 105 \\
(20)\end{array}$ & $<0.01$ \\
\hline Extensor digitorum brevis & $\begin{array}{c}6 \cdot 0 \pm 1 \cdot 9 \\
(20)\end{array}$ & $\begin{array}{c}3 \cdot 4 \pm 1 \cdot 5 \\
(20)\end{array}$ & $<0.001$ & $\begin{array}{c}203 \pm 57 \\
(20)\end{array}$ & $\begin{array}{c}78 \pm 41 \\
(20)\end{array}$ & $<0.001$ \\
\hline
\end{tabular}




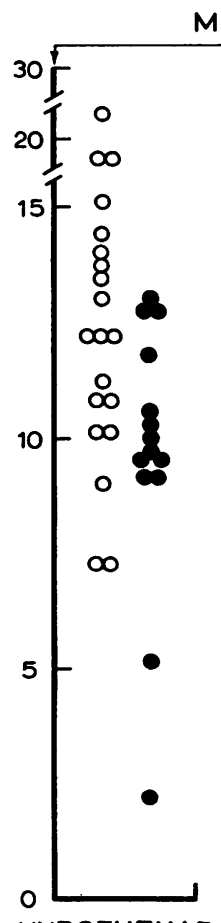

HYPOTHENAR
M WAVE (mV)

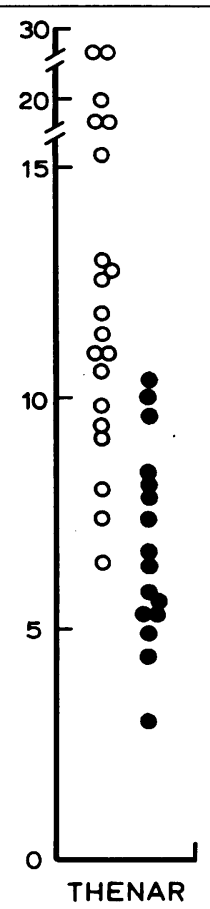

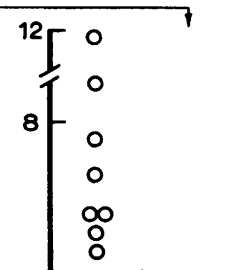

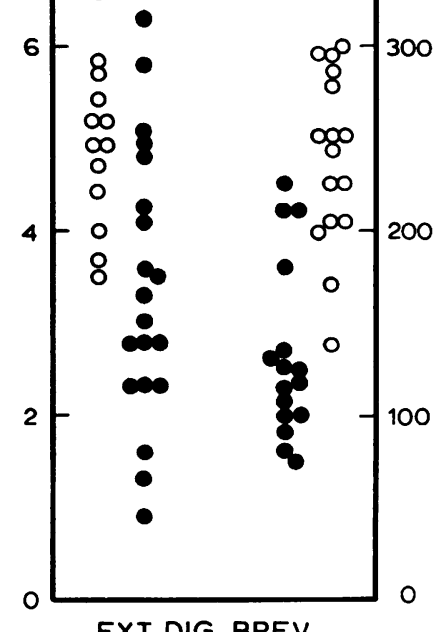

EXT. DIG. BREV.
FIG. 1. Maximal amplitudes of $M$ waves and isometric twitch tensions in muscles of patients with thyrotoxicosis (O) and controls $(\mathrm{O})$. Ext. dig. brev.: extensor digitorum brevis. was used to sample spontaneous and volitional potentials in selected muscles. A pre-amplifier with a passband from $2 \mathrm{~Hz}$ to $10 \mathrm{kHz}$ was used in conjunction with an oscilloscope time-base velocity of $10 \mathrm{~ms} / \mathrm{cm}$ and a vertical sensitivity of $100-500 \mu \mathrm{V} /$ $\mathrm{cm}$. All analysis of the displayed potentials was performed subjectively.

STATISTICAL ANALYSIS Means have been given with standard deviations throughout the paper. The significance of a difference between two means was calculated with Student's $t$ test, notwithstanding any skewing of the values about the mean. In the tables $P$ values greater than 0.05 have been shown as NS (not significant). Only values smaller than 0.01 have been regarded as definitely significant but intermediate values (between 0.01 and 0.05 ) have also been given in tables.

\section{RESULTS}

MUSCLE INVOLVEMENT IN THYROTOXICOSIS TWO simple electrophysiological tests were used to establish if weakness or wasting of muscles were present in the thyrotoxic patients. One involved measurement of the amplitudes of the maximum muscle potentials ( $\mathrm{M}$ waves) evoked by nerve stimulation and was applied to the extenso digitorum brevis (EDB), thenar, and hypothenar muscles. The second test was restricted to the EDB and, less commonly, the hypothenar muscles and was the determination of isometric twitch tension. The results of both types of investigation depend on the number of muscle fibres available for excitation and the values obtained experimentally are shown in Fig. 1. It can be seen from Fig. 1 that in a substantial fraction of the hyperthyroid patients the $M$ wave amplitudes and isometric twitch tensions fell outside the corresponding ranges of control results, the lowest values being found in the most severely affected patients with the greatest losses of weight. The mean EDB twitch tension 응 calculated for the 16 hyperthyroid patients was $133 \pm 48 \mathrm{~g}$ and was significantly smaller than the control mean $(285 \pm 102 \mathrm{~g} ; \mathbf{P}=<0.001)$. Inspec- N tion of Fig. 1 reveals that the proportional reduction in $\mathrm{M}$ wave amplitude was not equal for $\mathrm{N}$ the three muscles studied in each patient. The reduction was greatest for the EDB and thenar 


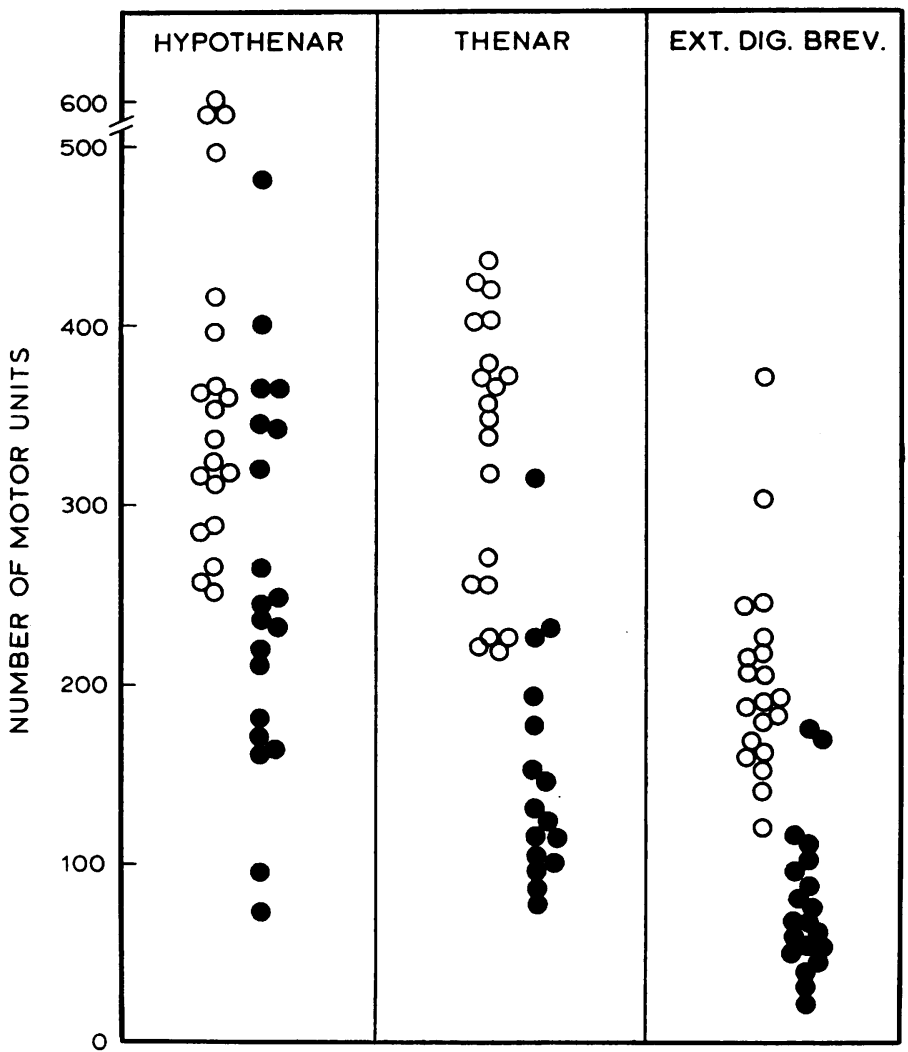

FIG. 2. Numbers of functioning motor units in muscles of patients with thyrotoxicosis $(\bigcirc)$ and controls (O). Ext. dig. brev.: extensor digitorum brevis. muscles and least for the hypothenar ones; the mean values and significance levels are set out in Table 1.

NUMBERS OF FUNCTIONING MOTOR UNITS The numbers of functioning motor units in the EDB, thenar, and hypothenar muscles were estimated using techniques described previously (see Methods). It was found that in all but two of the 20 hyperthyroid patients the EDB estimate fell below the lower limit of the control range $(120$ units) and the mean value of $78 \pm 41$ units differed significantly from the control mean $(203 \pm 57$ units; Fig. 2). Similarly, in 13 of the 16 patients tested, there was a loss of functioning thenar units and, again, the mean value of $149 \pm 64$ units was significantly reduced (Table 1 ). In contrast, eight out of 20 patients had normal hypothenar motor unit populations and the mean value, though still appreciably diminished, was closer to that of the controls. In all the thyrotoxic patients at least one of the motor unit estimates was reduced. In Fig. 3 an attempt has been made to show the relative involvement of the three types of motor unit population, using a simulated three-dimensional display.

Figure 4 also depicts numbers of functioning units, this time in six treated subjects. Five of these were now clinically euthyroid, each having been given a single dose of ${ }^{131} \mathrm{I}$ between 21 and 38 weeks before the second examination. The sixth patient (case 1) had been treated with propylthiouracil for eight weeks and, although improved, appeared to be mildly hyperthyroid. Of the 15 initially abnormal muscles only four still had reduced numbers of functioning motor units and in each of these the second estimate was appreciably larger than the first. It is of interest that normal results were found in the two patients who originally presented with exophthalmos but had no other evidence of thyrotoxicosis either on clinical or on laboratory 


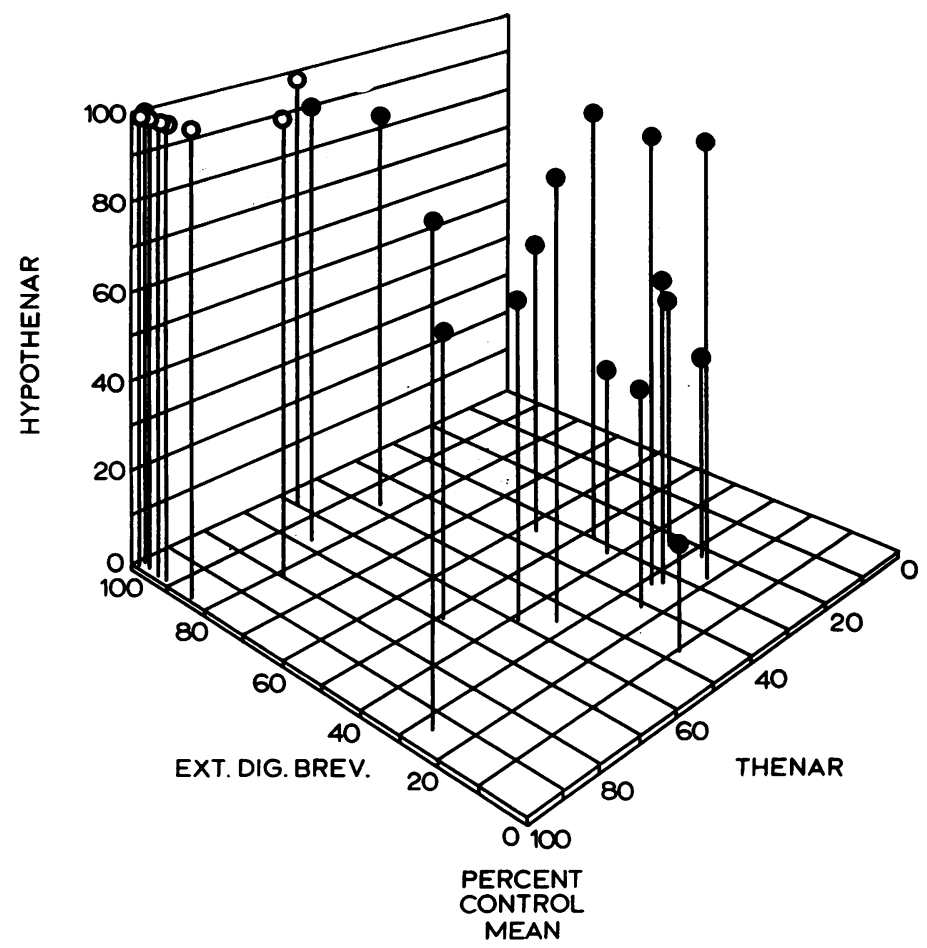

FIG. 3. Simulated three-dimensional representation of the relative involvement of motor unit populations in the extensor digitorum brevis, thenar, and hypothenar muscles of thyrotoxic patients (O). Also shown are values for the eight control subjects from whom data were available on all three types of muscle preparation $(\bigcirc)$. Values greater than $100 \%$ of control mean have been shown as $100 \%$. Note the more severe involvement of the EDB and thenar muscles in thyrotoxicosis, compared with the hypothenar group.

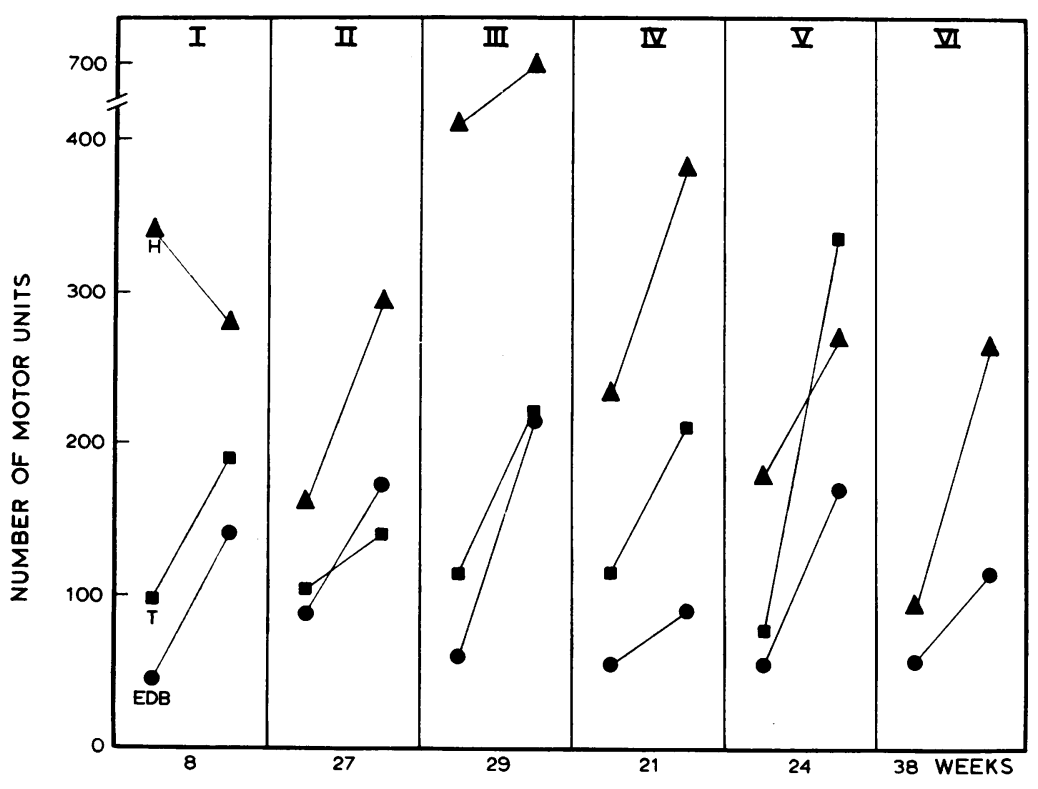

FIG. 4. Numbers of functioning motor units in six patients before and after treatment of their thyrotoxicosis. Duration of treatment indicated at bottom of each column. Results of extensor digitorum brevis (○), thenar ( $\square$ ), and hypothenar ( $\mathbf{\Delta})$ muscles. In each case the value at the right side is the second estimation. 


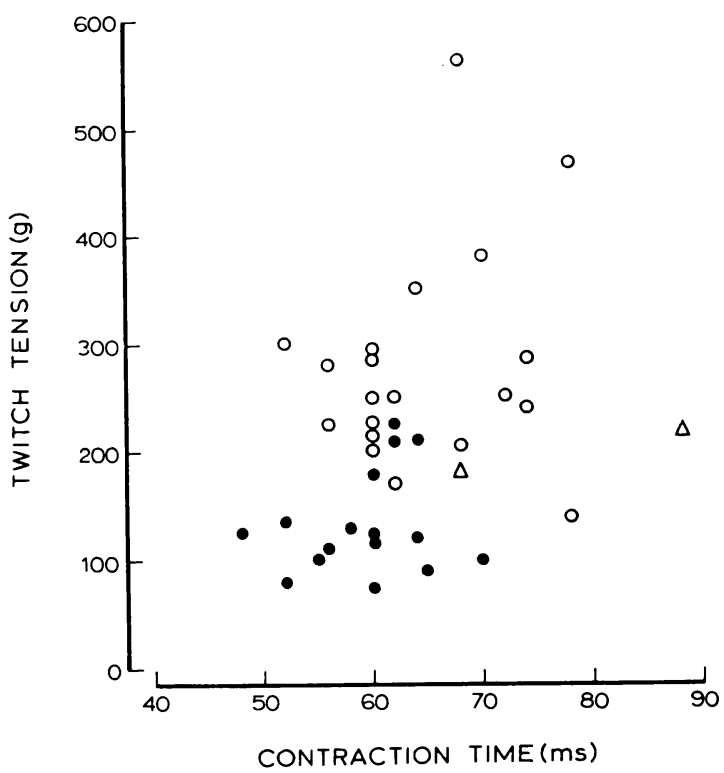

FIG. 5. Contraction times and maximum isometric twitch tensions of extensor digitorum brevis muscles in thyrotoxic patients $(\bigcirc)$, control subjects $(\bigcirc)$, and euthyroid patients with exophthalmos $(\triangle)$.

examination. In these patients the respective numbers of units were as follows; EDB, 144 and 394; thenar, 221 and 424; hypothenar, 532 and 361 .

SIZES OF SURVIVING MOTOR UNITS It is, of course, not possible to measure the sizes of the motor units directly but the amplitudes of the increments in the graded evoked potential give an indication of the relative sizes. It will be remembered that each increment is considered to have been generated by one motor unit (see Methods). Thus, assuming the fibre diameters did not change, the amplitudes of the increments should be directly proportional to the numbers of muscle fibres within the corresponding motor units. An indication of the sizes of the increments can be gained by comparing the mean numbers of units with the $M$ wave amplitudes for each muscle. In the EDB muscles, where 'denervation' was greatest, the potentials tended to be somewhat larger and the mean value $(44 \pm 31 \mu \mathrm{V}$, $\mathrm{n}=195$ ) was significantly increased (control mean, $30 \pm 21 \mu \mathrm{V}, \mathrm{n}=203, \mathrm{P}=<0.001)$. A smaller, but not significant, increase was observed for the thenar motor unit potentials while the hypothenar mean value was virtually unchanged.

TWITCH TIME COURSES The reductions in mean twitch tension of EDB muscles in hyperthyroid patients has already been described. The timecourses of the twitches are of special interest in thyroid disorders for it is well established that they are fast in hyperthyroidism and slowed in hypothyroidism (Lambert et al., 1951). In Fig. 5 the contraction times and twitch tensions have been plotted against each other and shown for control subjects as well as for patients with hyperthyroidism. It can be seen that, although most contraction-time values for the thyrotoxic patients were at the 'fast' end of the normal

TABLE 2

MAXIMAL IMPULSE CONDUCTION VELOCITIES AND RESPONSE AMPLITUDES OF SENSORY AXONS IN VARIOUS NERVES OF THYROTOXIC PATIENTS AND CONTROL SUBJECTS

\begin{tabular}{|c|c|c|c|c|c|c|}
\hline \multirow[b]{2}{*}{ Nerve } & \multicolumn{3}{|c|}{ 'Sensory' conduction velocity $(\mathrm{m} / \mathrm{s})$} & \multicolumn{3}{|c|}{ Response amplitude $\left(\mu V^{\prime}\right)$} \\
\hline & Controls & Patients & $P$ & Controls & Patients & $P$ \\
\hline Radial & $\begin{array}{c}53 \pm 6 \\
(31)\end{array}$ & $\begin{array}{c}49 \pm 7 \\
(17)\end{array}$ & $<0.05$ & $\begin{array}{r}26 \pm 7 \\
(31)\end{array}$ & $\begin{array}{r}23 \pm 7 \\
(18)\end{array}$ & NS \\
\hline Median (III) & $\begin{array}{c}55 \pm 5 \\
(31)\end{array}$ & $\begin{array}{c}56 \pm 5 \\
(18)\end{array}$ & NS & $\begin{array}{c}37 \pm 10 \\
(31)\end{array}$ & $\begin{array}{c}33 \pm 13 \\
(19)\end{array}$ & NS \\
\hline Ulnar (V) & $\begin{array}{c}55 \pm 5 \\
(29)\end{array}$ & $\begin{array}{c}52 \pm 7 \\
(18)\end{array}$ & NS & $\begin{array}{r}20 \pm 7 \\
(30)\end{array}$ & $\begin{array}{r}17 \pm 7 \\
(19)\end{array}$ & NS \\
\hline Sural & $\begin{array}{c}42 \pm 5 \\
(21)\end{array}$ & $\begin{array}{c}49 \pm 7 \\
(19)\end{array}$ & $<0.01$ & $\begin{array}{r}13 \pm 4 \\
(21)\end{array}$ & $\begin{array}{r}11 \pm 5 \\
(19)\end{array}$ & NS \\
\hline
\end{tabular}

Numbers of observations given in parentheses. The values for the median and ulnar nerves are those obtained by stimulation of the middle and little fingers respectively. 
TABLE 3

MAXIMAL IMPULSE CONDUCTION VELOCITIES IN MOTOR AXONS OF VARIOUS NERVES IN THYROTOXIC PATIENTS AND CONTROL SUBJECTS

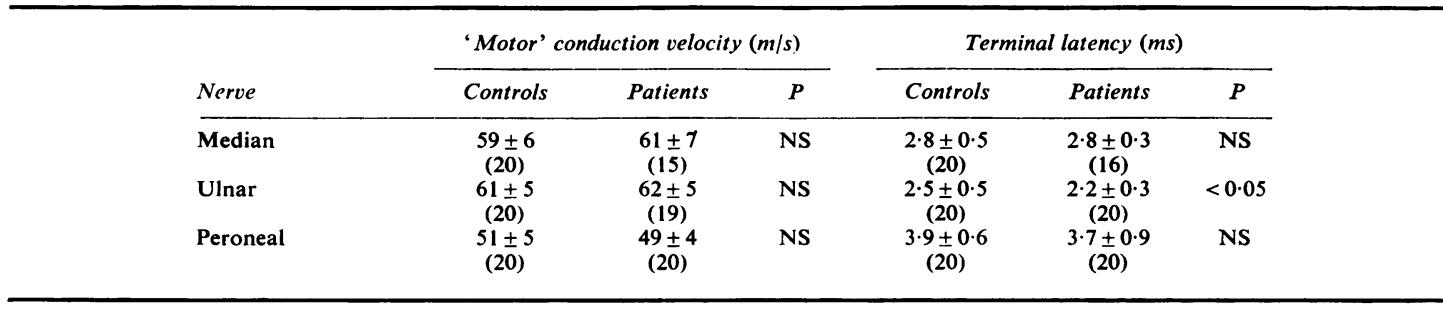

Also given are corresponding values for 'terminal latency'-that is, time elapsing between stimulus to distal region of nerve and onset of evoked muscle response. Numbers of observations given in parenthesis.

TABLE 4

RESULTS OF ELECTROPHYSIOLOGICAL EXAMINATION OF VARIOUS MUSCLES WITH CONCENTRIC NEEDLE ELECTRODES IN 13 PATIENTS WITH THYROTOXICOSIS

\begin{tabular}{|c|c|c|c|c|c|c|c|}
\hline & $E D B$ & $A P B$ & $Q U A D$ & $B I C E P S$ & $A D M$ & $T A$ & Total \\
\hline Total examined & 6 & 12 & 7 & 8 & 2 & 1 & 36 \\
\hline Normal & 0 & 7 & 6 & 8 & $\overline{1}$ & 0 & 22 \\
\hline Reduced pattern & 4 & 1 & 1 & 0 & 0 & 0 & 6 \\
\hline Fibrillations & 0 & 1 & $\mathbf{0}$ & $\mathbf{0}$ & 0 & $\mathbf{0}$ & 1 \\
\hline Fasciculations & 0 & 1 & 0 & 0 & 0 & $\mathbf{0}$ & 1 \\
\hline Brief potentials & 1 & 1 & 0 & 0 & 0 & 0 & 2 \\
\hline Prolonged potentials & 1 & 1 & 0 & 0 & 1 & 1 & 4 \\
\hline
\end{tabular}

spectrum, only one exceeded the limit of control range $(52 \mathrm{~ms})$. When the results for the hyperthyroid population were pooled, the mean contraction time $(59 \pm 6 \mathrm{~ms})$ differed significantly from the corresponding control value $(65 \pm 8 \mathrm{~ms} ; \mathrm{P}=<0 \cdot 01)$. In contrast, there was no significant difference between the mean halfrelaxation times for the thyrotoxic and control subjects $(56 \pm 10 \mathrm{~ms}$ and $53 \pm 10 \mathrm{~ms}$ respectively). In Fig. 5 it can also be seen that no correlation appeared to exist between the twitch tension and contraction time in either the normal or the thyrotoxic subjects. Of particular interest (see Discussion) was the observation that, in one patient with thyrotoxicosis, an EDB muscle with a normal number of units (171) had a relatively 'fast' twitch (contraction time, $52 \mathrm{~ms}$ ). In this subject the hypothenar group of muscles also had a full population of units and a fast twitch, while the thenar unit estimate was slightly reduced.
SENSORY AND MOTOR NERVE STUDIES The maXimum amplitudes of compound action potentials were measured in sensory fibres of the sural, radial, median, and ulnar nerves and are depicted in Table 2. It is apparent that neither the potential amplitudes nor the impulse velocities differed significantly between the control and hyperthyroid subjects. The single exception was the rather higher conduction velocity in sural nerves of thyrotoxic patients.

Similarly, Table 3 shows that the maximal impulse conduction velocities in motor axons of the median, ulnar, and peroneal nerves were very similar in the two populations, as were the terminal motor latencies.

SUPPLEMENTARY INVESTIGATIONS In each of 13 patients a concentric needle electrode was used to study at least one proximal and one distal muscle. Although the analysis of the recorded activity 
was performed subjectively, it was obvious that distal muscles such as the extensor digitorum brevis and the abductor pollicis brevis had much higher incidences of abnormality than proximal muscles such as biceps brachii and quadriceps (Table 4). The commonest abnormality was a reduction in interference pattern; fibrillations were observed in only one patient and fasciculations were also seen in a solitary case. In most muscles the volitional potentials appeared normal (Table 3 ) but they were clearly prolonged in four and were brief in two.

In three patients the responses were examined of the thenar or hypothenar muscles to indirect stimulation at 3 and 10 shocks/second. In each instance the muscle responses were unchanged or else showed a slight increase (maximum increase, $22 \%$ of initial value).

\section{DISCUSSION}

All the patients with thyrotoxicosis had evidence of a loss of functioning motor units and this was greatest in those most severely affected by the disease. Since most motor units were involved in an all-or-nothing manner, it was unlikely that the underlying disease mechanism was a myopathic one. Thus in the early stage of a myopathy, when muscle fibres should be affected in a random fashion, a normal number of rather smaller motor units would be anticipated. In this study, however, it was found that in the EDB or thenar muscles as much as three-quarters of the normal population of motor units could be destroyed while other units remained intact or were even enlarged. Such a selective involvement of motor units argued strongly in favour of a neuropathic process; a more detailed consideration of the significance of motor unit sizes in the pathogenesis of disease has been presented elsewhere in relation to muscular dystrophy (McComas et al., 1971; McComas et al., 1974). Further evidence of a neuropathic process was the enlargement of motor units noted in some patients of the present study. This observation suggested that some muscle fibres could continue to function if adopted by a 'fresh' motoneurone, thereby becoming part of a larger motor unit. In contrast with the results of Ludin et al., (1968) fibrillation potentials were an uncommon finding in the present study, being detected in only one of the 18 distal muscles examined.
If the disease process is indeed a neuropathic one, why were the muscles in any one patient affected to different extents? For example, there were a number of patients with significant involvement of the thenar and EDB motor units and in whom the hypothenar unit populations were barely affected. Unfortunately, it is not possible to answer this question satisfactorily at present, though it is clear from the unequal involvement of hand muscles that axonal length cannot be the sole factor determining the severity of neural involvement. It also appears that the relative sparing of hypothenar motor units is a phenomenon common to several varieties of neuromuscular disease since it has now been observed in ageing (Sica et al., 1974), muscular dystrophy (McComas et al., 1974), and chronic renal failure (Upton, McComas, and Shimazu, unpublished observations). In thyrotoxicosis the proximal muscles also seemed to be affected less severely, as judged by the normal findings during concentric needle electromyography and the normal motor unit estimates in soleus muscles (two patients studied). These observations were not in agreement with the results of other studies in which high incidences of abnormality were found in proximal muscles (Havard et al., 1963; Ramsay, 1966; see also Sanderson and Adey, 1952). However, since the analysis of concentric needle electromyography was performed subjectively in the present study, it is certainly possible that small but consistent abnormalities might have been overlooked.

The next question which might be asked concerns the site of the neuropathic lesion-is it in the axon, Schwann cell, or motoneurone soma? Lesions of the Schwann cell cause segmental demyelination and, as a consequence, slowed impulse conduction. In the present study, however, the maximal motor conduction velocities were normal and the absence of abnormal $M$ wave dispersion also suggested that surviving axons had little demyelination. Further evidence against the demyelinating process was the complete sparing of sensory nerve fibres in the arm and legs by the neuropathic process. While an axonal lesion could certainly explain the observed findings, we are tempted to identify the most biochemically active part of the motoneurone, the soma itself, as the likeliest site of the primary lesion in a metabolic disorder. If this 
identification is correct then the thyrotoxic neuropathy is but another example of a 'dyingback' process (Cavanagh, 1964). As yet, we do not know if it is simply the neuromuscular junctions which are no longer functional or whether the motoneurone axon can no longer transmit impulses towards them. It is certainly intriguing that, using intravital staining, Havard et al. (1963) were able to demonstrate swellings in the terminal motor axons together with clubbing of the end-plates.

How does hyperthyroidism inactivate the motoneurones? An important observation was that there was no loss of motor unit function in the two patients presenting with exophthalmos and in whom clinical examination and laboratory investigation failed to reveal evidence of hyperthyroidism. This suggested that the neuropathy was a true effect of thyroid hormone(s) rather than some associated feature of the hyperthyroid syndrome. In favour of this conclusion is the report of muscle weakness in an otherwise normal subject who had taken thyroxine to lose weight (Schwarz and Rose, 1963). Also, Hofmann and Denys (1972) were able to show that the muscle fibres of rats injected with triiodothyronine developed falls in resting membrane potential and often became inexcitable, even to direct stimulation.

The mechanism by which the thyroid hormones are able to disrupt function in the motoneurones cannot be analysed further by an electrophysiological approach. Nevertheless, on theoretical grounds, at least two possibilities can be advanced. One is that the thyroid hormones, by overstimulating the metabolism of the motoneurone soma itself, are able to 'exhaust' those biochemical reactions concerned with the trophic control of muscle fibres. The alternative mechanism is an indirect one in which the motoneurones become depleted of some essential substance used up by other 'hypermetabolic' cells. Some of these hypermetabolic cells will be muscle fibres themselves, for these are important contributors to the increased basal metabolic rate characteristic of hyperthyroidism. Part of the action of the hormone on the muscle fibres is reflected in the increased speed of contraction and relaxation during the isometric twitch. This speeding-up cannot be due to a selective loss of function in slow twitch units since in some muscles the fast twitches were associated with a normal population of units. Instead it appears from the work of Takamori et al. (1971) that the thyroid hormones are able to shorten the duration of the 'active state' phase of muscle contraction. It is possible that this shortening results from potentiation by thyroid hormones of activity at the betaadrenergic receptor sites which have been demonstrated within muscle fibres (Marsden and Meadows, 1970).

It is obviously important to establish whether or not the deleterious action of thyroid hormone on the motoneurone is reversible. The mere recovery of strength after treatment cannot be regarded as conclusive evidence for it is known that effective compensation for denervation can be achieved through axonal sprouting of surviving motorneurones. Fortunately, a clear answer has been obtained from observations on the six euthyroid, but formerly hyperthyroid, patients. In these patients nearly all the motor unit counts had re-entered the normal ranges after treatment with ${ }^{131}$ I or, in one case, with propylthiouracila Therefore the evidence presently available indicates that the motoneurone dysfunction i reversible.

The changes which take place in the muscle during the patient's recovery from thyrotoxicosis are of considerable interest. In four of the six patients studied a second time, it appeared that the restoration of muscle function had been achieved simply by the reactivation of previously 'inert' muscle fibres by 'recovered' motoneurones. In the two remaining patients, however, there was indirect evidence from a comparison of motor unit potential amplitudes and ' $M$ ' waves, that some remodelling of motor units might have taken place. In other words, muscle fibres which had been reinnervated by adoptive motoneurones during the period of thyrotoxicosis, had subsequently been recaptured by the recovered motoneurones. These observations would also imply that during the thyrotoxic phase a proportion of the muscle fibres may have had two end-plates, one original and quiescent, the other recent and functional. It seems important to explore this possibility further, since this type of finding may help to prove or disprove the existence of a system enabling highly specific recognitions to be made between motoneurones 
and muscle fibres in mammals (see also Cass et al., 1973).

Finally, it is interesting to speculate on the possible relationship between motoneurone dysfunction and the other recognized neuromuscular complications of thyrotoxicosis-myopathy, myasthenia gravis, and familial periodic paralysis. We have argued elsewhere that another class of myopathic disorders, the muscular dystrophies, are in fact neuropathies with secondary degeneration of muscle fibres (McComas et al., 1971). The motor unit studies which we have now carried out on distal muscles raise the possibility that in thyrotoxicosis also, the weakness and muscle wasting of proximal muscles is largely neuropathic in origin.

To incriminate the motoneurones exclusively, however, would be imprudent, for it is probable that thyroid hormones act on all the body tissues, including muscle (see above). That being so, the onset of functional denervation might merely signal the point at which a failing motoneurone was no longer able to supply sufficient trophic materials to keep pace with an increased consumption of the latter by its colony of hypermetabolic muscle fibres. In 'idiopathic' myasthenia gravis, too, there is already a growing suspicion that the underlying defect may reside in the motoneurone soma with the synaptic dysfunction occurring as a secondary event (McComas et al., 1971); again, it seems quite possible that the myasthenia of thyrotoxicosis may have a similar explanation.

The relationship between motoneurone dysfunction and hypokalaemic familial periodic paralysis has not yet been fully explored in this laboratory; however, one of us (R.E.P.S.) has observed a loss of functioning EDB units between paralytic episodes in two of three patients with the non-thyrotoxic form of this disorder (Sica and Aguilera, 1972). Even if the nature of the association between this condition and motoneurone dysfunction cannot be determined at present, the possibility of a causal relationship between motoneurone dysfunction and the myopathy, loss of motor unit function and myasthenia of thyrotoxicosis seems worthy of further investigation.

We are grateful to our colleagues, particularly Dr. F. Orr and Dr. W. C. Nicholas, for permission to study some of the patients included in this study. We are also indebted to Irene Csatari for secretarial services, to Bernice Crompton and Judy Leon (supported by the Muscular Dystrophy Association of Canada) for technical assistance, and to Klaus Fabich for illustrations. One of us (A.J.McC.) is a member of the Canadian Medical Research Council's Group in Developmental Neurobiology, with whom R.E.P.S. held a Post-doctoral Fellowship.

\section{REFERENCES}

Birket-Smith, E., and Olivarius, B. de F. (1957). Polyradiculomyopathia in transient thyrotoxicosis. Danish Medical Bulletin, 4, 217-219.

Bronksky, D., Kaganiec, G. I., and Waldstein, S. S. (1964). An association between the Guillain-Barré syndrome and hyperthyroidism. American Journal of Medical Science, 247, 196-200.

Brown, W. F. (1972). A method for estimating the number of motor units in thenar muscles and the changes in motor unit count with ageing. Journal of Neurology, Neurosurgery, and Psychiatry, 35, 845-852.

Campbell, M. J., and McComas, A. J. (1970). The effects of ageing on muscle function. Fifth Symposium on Current Research in Muscular Dystrophy and Related Diseases, London (Abstracts of Communications). Abstract No. 5. Muscular Dystrophy Group of Great Britain: London. 1970.

Campbell, M. J., McComas, A. J., and Petito, F. (1973). Physiological changes in ageing muscles. Journal of Neurology, Neurosurgery, and Psychiatry, 36, 174-182.

Cass, D. T., Sutton, T. J., and Mark, R. F. (1973). Competition between nerves for functional connexions with axolotl muscles. Nature, 243, 201-203.

Cavanagh, J. B. (1964). Peripheral nerve changes in orthocresyl phosphate poisoning in the cat. Journal of Pathology and Bacteriology, 87, 365-383.

Engel, A. G. (1972). Neuromuscular manifestations of Graves' disease. Mayo Clinic Proceedings, 47, 919-925.

Havard, C. W. H., Campbell, E. D. R., Ross, H. B., and Spence, A. W. (1963). Electromyographic and histological findings in the muscles of patients with thyrotoxicosis. Quarterly Journal of Medicine, 32, 145-163.

Hofmann, W. W., and Denys, E. H. (1972). Effects of thyroid hormone at the neuromuscular junction. American Journal of Physiology, 223, 283-287.

Lambert, E. H., Underdahl, L. O., Beckett, S., and Mederos, L. O. (1951). A study of the ankle jerk in myxedema. Journal of Clinical Endocrinology, 11, 1186-1205.

Ludin, H. P., Spiess, H., and Koenig, M. P. (1969). Neuromuscular dysfunction associated with thyrotoxicosis. European Neurology, 2, 269-278.

McComas, A. J., Campbell, M. J., and Sica, R. E. P. (1971). Electrophysiological study of dystrophia myotonica. Journal of Neurology, Neurosurgery, and Psychiatry, 34, $132-139$.

McComas, A. J., Fawcett, P. R. W., Campbell, M. J., and Sica, R. E. P. (1971). Electrophysiological estimation of the number of motor units within a human muscle. Journal of Neurology, Neurosurgery, and Psychiatry, 34, 121-131.

McComas, A. J., Sica, R. E. P., and Brown, J. C. (1971). Myasthenia gravis: evidence for a 'central' defect. Journal of Neurological Sciences, 13, 107-113. 
McComas, A. J., Sica, R. E. P., and Campbell, M. J. (1971). "Sick" motoneurones. A unifying concept of muscle disease. Lancet, 1, 321-325.

McComas, A. J., Sica, R. E. P., McNabb, A. R., Goldberg, W. M., and Upton, A. R. M. (1973). Neuropathy in thyrotoxicosis. New England Journal of Medicine, 289, 219220.

McComas, A. J., Sica, R. E. P., Upton, A. R. M., and Petito, F. (1974). 'Sick' motoneurones and muscle diseases. Annals of the New York Academy of Sciences, 289, 219-220.

Marsden, C. D., and Meadows, J. C. (1970). The effect of adrenaline on the contraction of human muscle. Journal of Physiology, 207, 429-448.

Ramsay, I. D. (1966). Muscle dysfunction in hyperthyroidism. Lancet, 2, 931-935.

Sanderson, K. V., and Adey, W. R. (1952). Electromyographic and endocrine studies in chronic thyrotoxic myopathy. Journal of Neurology, Neurosurgery, and Psychiatry, 15, 200-205.
Schwarz, G. A., and Rose, E. (1963). Neuromyopathies and thyroid dysfunction. Archives of Internal Medicine, 112, 555-568.

Sica, R. E. P., and Aguilera, N. (1972). Electrophysiological studies in hypokalemic periodic paralysis. Medicina (Buenos Aires), 32, 93-99.

Sica, R. E. P., and McComas, A. J. (1971). Fast and slow twitch units in a human muscle. Journal of Neurology, Neurosurgery, and Psychiatry, 34, 113-120.

Sica, R. E. P., McComas, A. J., Upton, A. R. M., and Longmire, D. (1974). Numbers of motor units in small muscles of the hand. Journal of Neurology, Neurosurgery, and Psychiatry, 37, 55-67.

Takamori, M., Gutmann, L., and Shane, S. R. (1971). Contractile properties of human skeletal muscle. Archives of Neurology, 25, 535-546.

Whitfield, A. G. W., and Hudson, W. A. (1961). Chronic thyrotoxic myopathy. Quarterly Journal of Medicine, 30, 257-267. 